http://jmscr.igmpublication.org/home/ ISSN (e)-2347-176x ISSN (p) 2455-0450

crossref DOI: https://dx.doi.org/10.18535/jmscr/v8i12.21

Journal Of Medical Science And Clinical Research

\title{
An Uncommon Granulomatous Infection in a Post Renal Transplant Patient
}

\author{
Authors \\ Dr Vasireddy Teja ${ }^{1 *}$, Dr Y.V.S. Prabhakar MD ${ }^{2}$ \\ ${ }^{1}$ Third year Post Graduate MD Department of General Medicine, NRI Academy of Medical Sciences, \\ Guntur \\ ${ }^{2}$ Professor MD Department of General Medicine, NRI Academy of Medical Sciences, Guntur \\ *Corresponding Author \\ Dr Vasireddy Teja
}

Third year Post Graduate MD Department of General Medicine, NRI Academy of Medical Sciences, Guntur

\begin{abstract}
Introduction: Nocardiosis is acute, subaute or chronic suppurative infection. Two characteristics of nocardiosis is its ability to disseminate to virtually any organ particularly to central nervous system.

Case Report: A 27 yrs unmarried female with 7 months history of post renal transplant (allograft), chronic hepatitis B viral infection on immunosupressants (tacrolimus, corticosteroids, mycophenolate mofetil) came to hospital with chief complaints of cough, fever since 2 months. Required investigations like complete blood picture, chest radiograph, computerised tomogram of chest were sent and diagnosed as non-resolving pneumonia and treated with antituberculos therapy. In between the treatment patient developed seizures hence magnetic resonance imaging of brain with magnetic resonance spectroscopy was advised which revealed granulomatous lesion. In view of non-resolving pneumonia computerised tomogram guided lung biopsy was done from the pneumonic patch which revealed nocardiosis. Hence, treatment with feropenam, co-trimoxazole, linezolid was initiated. After 2 months there is complete resolution of lung lesions and partial resolution of brain lesions.

Conclusion: Disseminated nocardiosis occurs in people with deficient cell-mediated immunity. The hallmark of cerebral nervous system nocardiosis is formation of a parenchymal abscess that can occur in any region of brain. For cerebral nervous system involvement one year of treatment is required.

Keywords: Nocardia, post renal transplant.
\end{abstract}

\section{Introduction}

Nocardiosis is usually an opportunistic infection and most commonly presents as pulmonary disease. $^{(1)}$

Nocardia are rarely seen as contaminant in the laboratory and each isolate must be carefully evaluated as to its clinical significance. ${ }^{(2)}$

Recognition of nocardia can be optimised by seeing filamentous, white to yellow to orange colonies with aerial mycelia and delicate, dichotomously branched substrate mycelia with a dissecting microscope. ${ }^{(2)}$

Cases of post renal transplant with disseminated nocardiosis are very rare and frequently not reported. MRI brain and CT chest and microbiological and pathological confirmation of nocardial infection are necessary for diagnosis. We report a case of disseminated nocardial 
infection in a post renal transplant presenting with chronic pulmonary features and with seizures who had achieved clinical improvement and recovery after anti-microbial therapy.

\section{Case Report}

27 years unmarried female 7 months post renal transplant (allograft), Chronic HBV infection on immunosuppresants (corticosteroids, MMF, Tacrolimus) came to hospital with chief complaint of fever which was insidious onset, intermittent, high grade, associated with chills and rigors and cough which was insidious onset, dry cough, a/w fever, not $\mathrm{a} / \mathrm{w}$ SOB, chest pain and with c/o involuntary movements of both upper limbs and lower limbs. The involuntary movements were $\mathrm{a} / \mathrm{w}$ loss of consciousness, tongue bite, and forth from mouth, vomiting, and headache. These involuntary movements were almost present throughout the day and even occurred in sleep. Not a/w urinary or faecal incontinence bs post 5 days of admission. Patient had past h/o fever with cough one week back required investigations done and diagnosed as left upper lobe pneumonia and treated with antibiotics (feropenam, clarithromycin). Patient is a known CKD-stage V (chronic glomerulonephritis), and renal allograft transplant was done 7 months and was on immunosuppresants. No history of previous blood transfusions. Patient was undergoing treatment Since 7 month's on-steroids, MMF, Tacrolimus for renal transplamt. Since 2 weeks on -antibiotics like feropenam and clarithromycin. Now in v/o nonresolving pneumonia patient is started onATT. On examination patient had- pallor+, no icterus, no cyanosis, no clubbing, no lymphadenopathy, No pedal edema. Vitaldata was pulse rate of $-80 \mathrm{bpm}$; blood pressure of 130/90mmhg and temperature was afebrile. On neurological examination patients pupils were reacting to light equally in both eyes, extraocular movements in both eyes were normal. Tremors of both hands, fine, rhythmic were seen, Power was 5/5 in all 4limbs, deep tendon reflexes were $2+$,Plantar was flexor bilaterally.
Investigations: Haemoglobin was $6.9 \mathrm{gm} / \mathrm{dl}$ and total count was 6600 cells/cumm, CT LUNG FOLLOWED BY CT GUIDED BIOPSY and contrast MRI brain was done.CSF analysis revealed: Appearance - clear, Cells 1 cell/cumm, $100 \%$ lymphocytes, Glucose $-32 \mathrm{mg} / \mathrm{dl}$, Proteins $146 \mathrm{mg} / \mathrm{dl}$, Globulins -Positive.

FIG 1: CONTRAST MRI SHOWING NOCARDIA L BRAIN ABSCESS

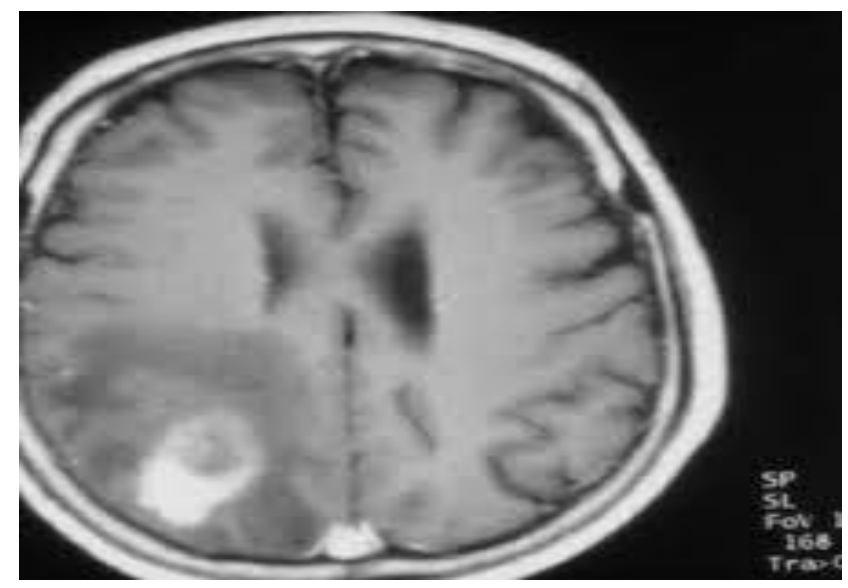

FIG 2: CT CHEST SHOWING PULMONARY NO DULE

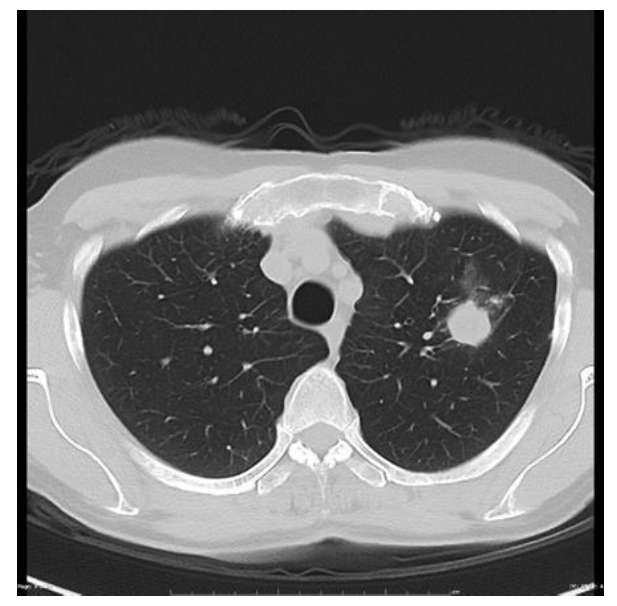

FIG 3: LUNG BIOPSY SHOWING THINBRANCH EDFILAMENTOUS STRUCTURE SV WIT GROC OT'SSTAIN

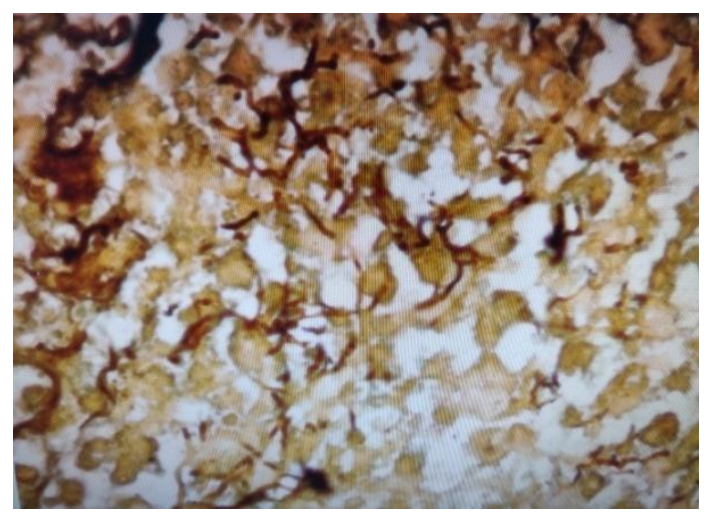




\section{Diagnosis}

A young post renal transplant patient on immunosupressants and known hepatitis b infection with clinical features and mri and ct and biopsy suggestive of nocardial infection.

\section{Discussion}

Although nocardia are frequently isolated during culture for mycobacteria, procedures used for decontamination of contaminated specimens submitted for mycobacterial culture may be deleteriuos to the nocardia. ${ }^{(3)}$

Oppurtunistic infections caused by nocardia often afflict immunocomprimised individuals like patients receiving chemotheraphy including aids and organ transplant recipients. ${ }^{(4)}$

Disseminated, particularly to central nervous system is relatively common and can be life threatening, eith mortality rates as high as $85 \%$ in immunocomprimised individuals. ${ }^{(5)}$

In some cases concomitant nocardial and tubercular infections have also been observed and are more likely to occur in immunocomprimised patients. $^{(6)}$

Diagnostic difficulty is compounded by its ability to disseminate to various sites after primary infection and this makes the type and site difficult to identify often requiring invasive biopsies. ${ }^{(7)}$

Virulence in nocardia has been attributed to its ability to survive and grow in variety of human cells and evade the host immune response by production of catalase and superoxides, inhibition of phagosome-lysosome function, decrease of intracranial acid phosphatase levels in macrophages and secretion of toxins. ${ }^{(8)}$

Once diagnosed, treatment of nocardiosis is usually prolonged because of the risk of relapse. ${ }^{(9)}$ Six to 12 months of antimicrobial therapy for immunocompetent patients and a minimum of 12 months for immunocomprimised of those with central nervous system dissemination is often recommended. ${ }^{(10)}$

Cootrimoxazole is the treatment of choice for nocardial infections. ${ }^{(11)}$
Imipenam and amikacin and third generation cephalosporins are also used and combination therapy can yield better results. ${ }^{(12)}$

\section{Conclusion}

Disseminated nocardial infection is rare but should be considered in the differential diagnosis in immunocomprimised patients. Clinical manifestations should be considered the essential basis for early diagnosis and treatment in order to reduce permanent disability.

The recommended treatment of this is long term antimicrobial therapy.

\section{References}

1. Michael A, Saubolle et.al. Nocardiosis: Review of clinical and laboratory experience. Journal of clinical microbio, Oct 2003, p:4497-4501.

2. Saubolle M.A. Aerobic actinomycetes, K.D. Mcclatchey, clinical laboratory medicine, $2^{\text {nd }}$ edition Lippincott William and wilkins. Philadelphia. 2002,p:12011202.

3. Murray P.R, R.L. Heeran et al. Effect of decontamination proed on nocardiaspecies. J Clin Microbiol 25:2010-2011.

4. Heer H. Mehta et al. Pathogenic nocardia: A diverse genus: Emerging pathogens or just poorly recognised. Plos Pathogens, march 5,2020 .

5. Wilson jee. Nocardiosis. update and clinical overview. Mayoclinproc 2012, 87(4):463-7.

6. Ekrani A, Khosrani AD, et al. Nocardia coinfection in patients with pulmonary tuberculosis, Jundishapur J Microbiol 2014; 7(12):e-12495.

7. Bell $\mathrm{M}$ et al. nocardiosis. antimicrobiome. July 11,2019.

8. Danis Schihienshicetal, interaction of nocardia asteroided with rabbit alveloar macrophages: aero of virulence, viability, ultrastructural damage.1980;28(2);610-9. 
9. Saubolle et al nocardiosis: review of cli and lab. J Clin Microbiol. 2003;41 (10): 4497-501.

10. Coussement J, Lebeaux D et al,nocardia infection in solid organ transplant recipients: A multicenter european case study. Clin infect dis ,2016,63:338-45.

11. Zhao P, Zhang $X$ et al. Susceptibility profiles of nocardiaspp. To antimicagents. Sci rep:2017(7):43660.

12. Poonyagariyagron $\mathrm{HK}$ et al. Challenges in the diagnosis and management of nocardiaonfection in lung transplant patient. Transpl infect dis:2008;10:403-8. 